\title{
Enterprise System as Business Intelligence and Knowledge Capabilities for Enhancing Applications and Practices of IT Governance
}

\author{
Firas M. Alkhaldi, Amman Arab University, Amman, Jordan \\ Samir M. Hammami, Dhofar University, Salalah, Oman \\ Saleh Kasem, Libyan Mediterranean University, Istanbul, Turkey \\ Abdullah Rashed, Independent Researcher, Sana'a, Yemen \\ Mansour Naser Alraja, Dhofar University, Salalah, Oman
}

\begin{abstract}
According to different views in information systems and the socio-technical perspective, many organizations was led to redefine their business with a more focused IT solutions, this study suggested a number of confirmatory measurement models that establish the ground for the hypothesed research constructs, and utilized the structural equation modeling techniques to test and validate the research hypotheses. The research present the results of a practical investigation of the influence and the effect of enterprise systems role applications and organizational knowledge capabilities on IT governance practices by enhancing its application and usability within the organization. The study suggests that smart enterprise systems capabilities (infrastructure scalability, planning alignments, and HR planning and professional capabilities the IT staff) and knowledge organizational capabilities (individual, managerial, and collaborative) have a positive dynamic influence on IT governance activities. It's also observed that enterprise systems role applications have a more profound influence on organizational knowledge capabilities (OKC) comparing to IT governance (ITGOV), where OKC played a significate additive role in mediating the effect and thus provided an enhanced extra effect on IT governance.
\end{abstract}

\section{KEYWORDS}

Business Intelligence, Confirmatory Factor Analysis, IT Governance, Organizational, Knowledge Capabilities, Smart Enterprise Systems, Structural Equation Modeling

\section{INTRODUCTION}

Advanced information systems applications and practices such as enterprise systems, business intelligence, knowledge management systems and IT governance are being utilize by enormous organizations, taking advantages and maximizing the benefit of the invested organizational recourses in such technology (Peters et al., 2016). As this trend is moving forward and increasing in term of 
the invested recourses, it is essential to assess whether the ultimate outcomes matches the diverse requirements desired, so as to advance the organizational performance by implementing such systems and to help the decision makers to take effective and efficient decisions (Chan \& Rosemann, 2001; Gallinucci et al., 2015). Giving the research trends and the importance of this topics, there are a thought-provoking need for coherent theoretical and empirical models to address the gaps and justify relations and to direct future research that guides the development and the justification of various relationships between enterprise systems, knowledge management, and IT governance application by applying a systematic empirical investigation of the relationships (Hammami \& Alkhaldi, 2012; 2017).

\section{LITERATURE REVIEW}

Grant \& Chen (2005) stated that knowledge views of the firm examine the wealth of the organization as a mixture of a numerous resources and describes how organizations obtain the needed value out of these resources, in addition; (Blome et. al., 2014) indicated that organizations should be the venue of unremitting advances and grouping of business resources of both tangible and intangible. Kubina, et.,al, (2015) recognize that business intelligence can be introduced as a form of integration of knowledge management and information system within organizations as it would be of a good effect it should be fostered as it's not programmed. Other important concerns is about knowledge management as it seen as the a strategic growth aspect of an organizations, as it's encompasses an obvious and determined demonstration of knowledge of the disseminated groups of individuals in the organization (Hammami \& Alkhaldi, 2012), in order to advance the business actions as it is a dynamic issue of the organization as a whole. Advancing the success of IS of the organization is critical as the new goal should be leading the organization to appreciate knowledge work (Abate, 2009), where the success of business intelligence system requires the incorporation of information system strategy and knowledge core competences (Tseng, 2014) to establish IT/Business alignment (Breschi et.al., 2003).

\section{Enterprise Systems as Business Intelligence and Human Factor}

Business intelligence (BI) as an advance form of information applications and IT solutions, is consider to be the core of the system activities of many modern business entities, that pursues a healthy and growing performance. Ogiela and Ogiela (2014) stated that it is an absolute necessity to advance the overall organization-wide performance, where this notion has developed to be a tactical tool that permits business to grow beyond the boundaries of its legacy systems (Tanev et. al., 2015). Azma and Mostafapour, (2012) outline that IT /business alignment, the professionalism and the knowledge expertise of IT teams along with performance, reliability and flexibility are central characteristics of BI systems. Rowley (1995) call for the planning for a strategic information system that its key feature is to accomplish success for decision makers, using deep analysis of the organization environment as indicated by (Brown, 2006) and supported by intensive efforts to enhanced analysis of the internal tasks of the organization spanning over its various course of actions and technologies (Grovera \& Segarsb, 2005; Lederer \& Sethi, 1988). IT experts, professionals and knowledgeable workers were also seen as imperative and pivotal to the success of business intelligence initiatives (Moriarty, 2015). This suggestion is also in agreement with the assessments of (Luftman et. al., 2004) where they claimed that various skills are essential to the successful formation of the IT professionals such as the ability to examine and review business vision, team working skills, self-development as well as their IT expertise as it will improve the rate of success to IT projects. To conclude business intelligence is a mixture of traits that characterize an agile and smart infrastructure, planning, and HR IT planned expertise and knowledge, the key attributes can be seen as the following: 
- Smart Infrastructure: Flexibility, Availability, Scalability, Reliability, Performance

- Planning: Alignment, Analysis, Cooperation, Improvement in Capabilities

- HR Planned Expertise and Knowledge: IT Human resources planning that can assist in system development, Rational assignment of IT professional into business, Professional capabilities the IT staff

\section{Organizational Knowledge Capabilities}

Organizational knowledge intentions in to enrich the superiority of business activities by active supervision of the numerous organizational information resources that reside within and external to the enterprise as business practice and not only a pure technological solution, where a novel knowledge will be created. Calvo-Mora et.,al., (2015) and Al-Zayyat et. al., (2009) argued that business performance lag the technology solutions and he suggest that the answer can be seen in KM application which will affect through its potential and lead to an improve business processes performance. Thus, it infers that the development of business processes will be a significant aspect in understanding the how and where knowledge advances the performance of the business activities. Consecutively, the process can be executed by getting familiar with the status of the knowledge desired to aid the required actions or implement specific decisions that reflect the process, along with considering the related knowledge produced by those decisions and actions. Estrada et. al., (2015) assert that if knowledge cannot be shared with others, it is nearly useless. It come to be extremely valuable and action oriented if and when it's disseminated and used across an organization. The nature and the state of the knowledge communicated must be linked to the related management level; strategic level, tactical level and the operational level. According to Ghani and Zakaria (2013) for a business processes to make profits, to add value, knowledge assets is needed, which is the knowledge concerning markets, products, technologies and organizations, that a business has or needs to have.

Organizational knowledge is not about handling knowledge assets, it is also about dealing with the practices that act upon these assets as well. McGinnis and Zhenyu (2007) call for continuous improvement efforts to the issues of post implementation of information systems to insure a success of implemented system by adopting methodological efforts of system development. This is coincided with SECI model of Nonaka and Konno (1998) where they claimed that knowledge will improve the chance of system deployment by adding new insights. Knowledge sharing intention is also seen as key imperative issues of organizational knowledge (Cunningham et. al., 2015). Moreover, Urban (2015) anticipated that understanding knowledge friendly culture is the core to assist reaching the success of business strategies by helping to develop the organizational and information infrastructures, and in order to achieve the basic objectives of the available resources like people, machines, methods, money and information systems, all should be brought together. Organizational structure is needed as a facilitator to the relationship between the various stakeholders, by facilitating knowledge work processes and help communications between staff to boost sharing and generation of new knowledge (Adenfelt \& Lagerstrom, 2006; Cohen and Olsen, 2015; Mao, 2016). Knowledge culture was argued by numerous authors (Davy, 2006; Huotari \& Iivonen, 2004; Lucas, 2005) as shared values, perceptions that are believed by the organizational staff and reveals the norms and philosophies that direct and control their behavior. Moreover, traits of knowledge culture comprise a clear comprehension of the worthiness of KM practices, management support for KM at all levels, incentives that reward knowledge sharing, and inspire interaction (Malhotra, 2005; Nabuco et. al., 2006; Toledo 2016). Thus, it can be concluded that for OKC to succeed it must embrace number of traits oriented around Individual, Managerial, and Collaborative, and the key attributes can be seen as the following: 
- Individual Knowledge Capability: Reputation, Sociality, Willingness and intention to share knowledge, Employee Adaptability, and Integrity, and Employee Qualifications

- Managerial Knowledge Capabilities: Mentor, Facilitator, Innovator, Fosterer, Motivator, Learning advocate, Developer, and knowledge Dealer

- Collaborative Knowledge Capabilities: Culture, climate, structure, trust, and incentive

\section{IT Governance}

Business executives and IS/IT professionals are constantly challenged to bring about more influential, agile and effective systems and processes to reflect the ever-growing business desires and guidelines (Alreemy et.al., 2016). Information systems is considered as the furthermost significant capitals in any business (ITGI, 2008) and governance need to be develop around the core enterprises activities. The parts that IT plays in the total governance structure in organizations are progressively becoming crucial to competitive superiority (Al Qassimi \& Rusu, 2015; Pereira \& da Silva, 2012). Business executives and leader are recognizing the significant impacts and the leverage that IT have on their organization (Delone \& Mclean, 2003; ITGI, 2007. IT Governance as an integral structure of the corporate governance as stated by (Alreemy, et. al., 2016) and it is defined as a concept used to describe the organizational processes that formulate the actions that deals with the organization and utilization of the IT assets and capabilities (de Souza, et. al., 2014) and to achieve better decisions through IT (Pereira \& da Silva, 2012).

The drive of IT governance is to guide IT actions, to be certain that IT performance reflect the efforts and to take advantages of opportunities of the business that lead to the expected benefits. Utilizing IT resources responsibly and managing risks appropriately is a focal interest of the IT governance. IT governance is about the participation of decisional efforts of a number of individuals such as leaders, managers, executives, board of directors and stakeholders (de Souza, et. al., 2014). Understanding the concerns and the strategic value are the general goals of IT governance, thus aiming to ensure that the organization will continue its activities and to assist in the implementation of the schemes necessary to sustain its operation into the future, ensuring that anticipation for IT are realized, performance is accounted for, risks are lessened, and resources are managed. Al Qassimi and Rusu, (2015) pointed out that IT governance process started with deciding the business' IT objectives, and then provide the initial direction, where continuous circle is started so objectives can be linked and compared to performance, consequently leading to a redirection of operations as required and to a modification of goals as needed.

\section{IT Governance Framework (COBIT)}

Several leading IT governance frameworks are used worldwide, each of them has its own strengths and weaknesses in the context of competitiveness, corporate governance demands and regulatory requirements. Such as COSO, COBIT, ITIL, ISO15000, ISO17799, AS8015, GAISP, BS7799 and CCBF which was introduced by (Chang et.al., 2013) as a new framework for performing cloud computing business which is very relevant to IT/business strategic alignment, also a this trend is supported by (Chang et al., 2016) who established the cloud computing adoption framework (CCAF) which is security suitable for business clouds, in addition to business intelligence as a service (BIaaS) which was also discussed by (Chang, 2014) as an approach to compute risk and pricing for financial analysis and stock markets. One of the most successful IT governance frameworks is COBIT which was introduced by IT Governance Institute (ITGI). According to ITGI (2007) it recognizes around thirty-four IT processes and regulatory points that are commonly embraced by many business, each of these processes was linked to a business and IT goals that are intended to support (Lunardi et. al., 2014). COBIT is designed to provide comprehensive requirements where every IT process is designed to empower decision makers to advance the expected value or mitigate and/or eliminate risks, and help in improving the organizational structures, procedures, practices, and policies (Voon \& Salido, 
2009). COBIT support business entities to realize and appreciate the standing of their information systems, and assist mangers to agree on which and what levels of control the enterprise should practice through a designated maturity models that enables bench-marking, and pointing out the essential competence and metrics needed for improvements, bridging gaps of technical and organizational issues, performance and goals attainment of the IT processes that are need to accomplish both business and IT goals using various measurement principles (Goldman \& Ahuja, 2009; ITGI, 2007).

COBIT is a good practice support a distinct policy exploitation and control across and enterprises, and it underlines the regulatory abidance, and helps organizations maximize the value derived from IT. Hence, adopting COBIT or any IT governance framework will strengthen the comprehension of business objectives and improve communication of best practices (Rodríguez \& Son, 2014). The main pillars of IT governance that are adopt here in this study are based on COBOT framework, and the key attributes can be seen as the following:

- It/Business Strategic Alignment: IT strategy and operations must be lined up and incorporated first with business objectives and operations, then strategy and objectives are to be interpreted as operational tasks, and this must be accompanied by a distinct commitment from the organizational leaders. Furthermore, for IT strategy to be carried it requires a clear implementation against IT standards and policies (El-Mekawy et. al., 2015). Business executives establish the actual strategic worthiness of IT as it will be also a business concern to them monitoring if IT effects spillover to other non-IT business goals. Rezaee (2016) indicated that to ensure business continuity, IT/ Business alignment is of great importance for decision maker and must be considered in any business strategy;

- Business Value Delivery: Doherty et.al., (2015) stated that value delivery is in the implementation of value scheme in the entire process cycle, making sure that IT delivers the anticipated objectives as anticipated by the strategy, with a focus on the optimization of costs and showing the inherent value of IT (Pang, 2014). This notion has been also supported by (Biswas, 2014; Pereira \& da Silva, 2012; and Zhu et. al., 2015);

- Resource Allocation: Is about the maximizing and attaining an ideal investment through a good management of significate IT resources such as applications, infrastructure, data, and staff (Al Qassimi \& Rusu, 2015). The crucial aspects here, for a positive IT performance to be is through an optimal investment and the efficient and effective utilization and allocation of IT resources, as it servicing the needs of the enterprise. Many enterprises failed short of achieving the optimal level of proficiency of its IT budgets and assets (Bowman, et. al., 1983; Boynton \& Zmud, 1987; ITGI, 2003; Zhang \& Harte, 2015);

- Risk Management: Is a crucial activity needed in the organizational in order to realize the intended productivity and invention objectives in the organizations (Drucker, 1999). It requires full awareness of the corporate leading managers, along with strong knowledge of the enterprise's risk orientation, and full assurance of compliance necessities and transparency (Aven, 2015);

- Performance Measurement: Is in the process for the tracking and monitoring strategy implementation, it's about observing, evaluating, and reporting of activities to enhance and empower management. It can be also related to productivity, efficiency, effectiveness, quality. Performance measurement can be related to tasks, groups, individuals, and projects (Hyder \& Hebl, 2015). According to (Gerschewski \& Xiao, 2015) governance layer of an enterprise will assure that implementation of an effective and appropriate measures which in turn will address the various concerns of the top management.

\section{RESEARCH MODEL AND HYPOTHESES}

According to literature analysis; the researchers proposed a research model as in Figure 1 and the hypotheses were formed as follows: 

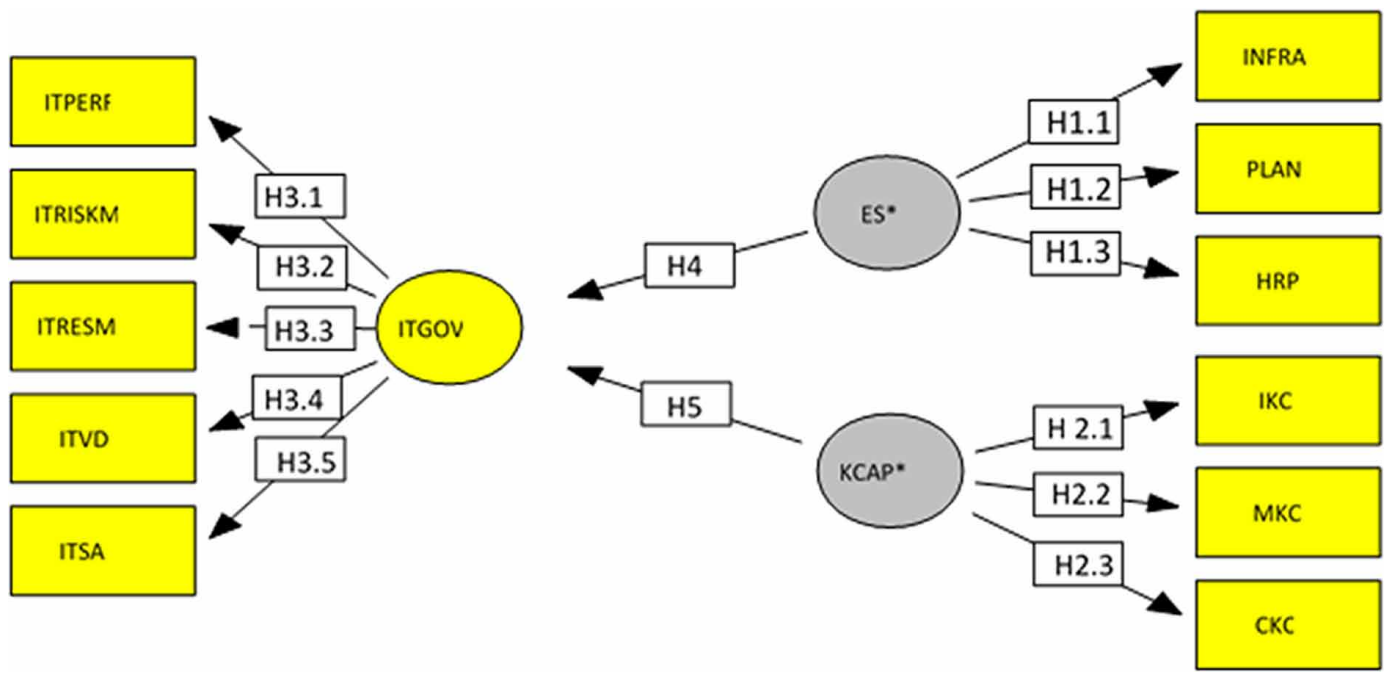

Hypothesis 1: Enterprise Systems as business intelligence is significantly and positively explained by its traits (Enterprise Systems' Infrastructure readiness, Enterprise Systems' Planning and Enterprise Systems' Experts readiness).

Hypothesis 2: Organizational knowledge capabilities is significantly and positively explained by its traits (Individual. Managerial, and collaborative) traits.

Hypothesis 3: IT Governance is significantly and positively explained by its traits (Alignment, Value Delivery, Risk Management, Resource Allocation, and Performance Measurement).

Hypothesis 4: There are a positive valid association between Enterprise Systems (BI) and IT Governance.

Hypothesis 5: There are a valid association between organizational knowledge capabilities and IT Governance.

\section{RESEARCH METHODS}

A quantitative approach was used in this study; and a structural equation modeling technique and factor analysis were also adopted to assess the proposed relationships in the research model. The data is acquired using a survey questionnaire technique as it is intended to examine the rationality of the proposed research hypotheses, the questionnaire was distributed to individuals with different management ranks (senior, executives, and managers) within organizations in both private and public sectors of selected countries in the middle esat, with a valid working enterprise system and an IT department that manages IT related works, the questionnaire was collected of sample of 510 respondents that met the required testing criteria.

\section{Model Validity}

The model validity was achieved via three tests of commonly used validity measures: content validity, convergent validity, and discriminate validity. Content validity was achieved by pilot-testing and subject expert review to assure the appropriateness among the measurement objects and the associated literature. Convergent validity was attained via examining the "composite reliability" as in the average variance as indicated by (Hair, et. al, 2010). The researchers also established the discriminate validity of Measurement Model by examining the average variance square root. 


\section{Normality}

The normality test is used to assess the value of the data distributions that matches up with the bell shaped normal distribution, the values of kurtosis, skewness, and Standard Deviation are deemed to be the determining indicators of data normality. For Skewness value, it indicates the symmetry of the distribution where Kurtosis value is to measure the flatness and peaked of the sample data with reference to a bel shaped normal distribution, both values has to be less than 1, while Standard Deviation must not exceed three SD values. Table 1 shows the results, as sample met the normality requirements.

\section{DATA ANALYSIS}

Structural Equation Modeling (SEM) is an advanced data analysis techniques were used for validating and measuring the statistical validity (Gefen et. al., 2000). SEM facilitates the analysis of the path regression and measurement model, and also it facilitates the analysis by integrating hypotheses testing with the concept of confirmatory factor analysis methods in one integral process. The outcome considered to be of a more precise examination of the proposed research model. SEM techniques offers an enhanced information about how data reflected on the hypothesed structural model than any other traditional testing methods (Gefen et. al., 2000).

\section{The Model Components}

The research model encompasses three constructs as follows:

- Smart Enterprise Systems(BI) was derived as a sum scale measure consist of three elements as follow:

- Enterprise Systems' Infrastructure readiness;

- Enterprise Systems' Planning;

- Enterprise Systems' Experts readiness;

- Organizational knowledge was derived as a sum scale measure consist of three elements:

- Individual knowledge capabilities;

- Managerial knowledge capabilities;

- collaborative knowledge capabilities;

Table 1. Normality test

\begin{tabular}{|l|l|l|l|l|l|}
\hline \multicolumn{1}{|c|}{ Construct } & \multicolumn{1}{c|}{ Item } & \multicolumn{1}{c|}{ Mean } & \multicolumn{1}{c|}{ Skewness } & \multicolumn{1}{c|}{ Kurtosis } & \multicolumn{1}{c|}{ Standard Dev. } \\
\hline \multirow{4}{*}{$\begin{array}{l}\text { Enterprise Systems as } \\
\text { business intelligence }\end{array}$} & INFRA & 3.77 & -0.75 & 1.14 & 0.7 \\
\cline { 2 - 7 } & PLAN & 3.46 & -0.66 & 0.63 & 0.79 \\
\cline { 2 - 7 } & HPP & 3.55 & -0.56 & 0.44 & 0.71 \\
\hline \multirow{4}{*}{$\begin{array}{l}\text { Organizational } \\
\text { knowledge capabilitie }\end{array}$} & IKC & 3.67 & -0.64 & 0.73 & 0.71 \\
\cline { 2 - 7 } & KMC & 3.44 & -0.63 & 0.42 & 0.82 \\
\cline { 2 - 7 } & CKC & 3.29 & -0.31 & -0.19 & 0.77 \\
\hline \multirow{5}{*}{ IT Governance } & ITSA & 3.47 & -0.66 & 0.76 & 0.72 \\
\cline { 2 - 7 } & ITVD & 3.35 & -0.42 & 0.27 & 0.72 \\
\cline { 2 - 6 } & ITRESM & 3.48 & -0.65 & 0.95 & 0.69 \\
\cline { 2 - 6 } & ITRISKM & 3.3 & -0.52 & 0.48 & 0.77 \\
\cline { 2 - 6 } & ITPERF & 3.48 & -0.54 & 0.75 & 0.67 \\
\hline
\end{tabular}


- IT Governance was derived as a sum scale measure consist of five elements:

- System Alignment;

- Value Delivery;

- Resource Allocation;

- Risk Management;

- Performance Measurement.

\section{Model Fitness}

Fit indexes measure the degree to which the collected data predicted the hypothesed proposed model. SEM tools and techniques was adopted to investigate and analyze the study model. EQS 6.1 application was used to examine the validity of the confirmatory factor analysis and the model structure. The findings of the analysis are reported in Table 2.

Although $\mathrm{Chi}^{2}$ value is tested not significant, and is was neglected as it was effected by the large sample. All fit measures as in Table 2 representing the adjusted model is well structured and accepted, hence, the adjusted structural model as shown in Figure 2 was adopted and approved for testing hypotheses.

\section{Confirmatory Model Testing}

A number of methods were used to examine the model hypotheses such as the Coefficient of determination $\left(\mathrm{R}^{2}\right)$ and the standardized coefficients (beta) which is used to predict the scale of the effect, as if it is near zero it reflects a weak relationship, and as it moves closer to 1 it means that the relationship is getting stronger. The results are shown in Table 3 and Figure 2.

\section{Enterprise Smart Systems (BI) Confirmatory Measurement Model Analysis}

Enterprise smart systems (BI) measurement model was used to examine the first hypothesis in the research which is questioning whether a noteworthy relation between enterprise systems (BI) and its elements (infrastructure (INFRA), Planning (PLAN), and Human resource planning (HRP) exists. Validating the significant relationships between the three elements and ES (BI) systems using statistically validated beta as the measurement of magnitude of the relationship. As in Table 3, the

Table 2. Model statistical fitness indexes

\begin{tabular}{|c|c|c|c|}
\hline \multicolumn{4}{|c|}{ FIT Indexes } \\
\hline Index & Label & Accepted Level & Calculated Values \\
\hline $\mathrm{CHI}^{2}$ & $X^{2}$ & - & 137.8 \\
\hline Degree of freedom & $d f$ & - & 39 \\
\hline Probability & $P$ & $\mathrm{P} \geq 0.05$ & 0.00 \\
\hline Normed Fit Index & $N F I$ & $\geq 0.90$ & 0.96 \\
\hline NonNormed Fit Index & $N N F I$ & $\geq 0.90$ & 0.96 \\
\hline Comparative Fit Index & $C F I$ & $\geq 0.90$ & 0.97 \\
\hline Bollen's Fit Index & $I F I$ & 0 to1 & 0.97 \\
\hline Goodness of fit index & $G F I$ & $\geq 0.9$ & 0.91 \\
\hline Adjusted Goodness of fit index & $A G F I$ & $\geq 0.9$ & 0.96 \\
\hline Standardized RMR & $S R M R$ & $\leq 0.05$ & 0.03 \\
\hline Root Mean Square Error of Approximation & RMSEA & $\leq 0.1$ & 0.07 \\
\hline
\end{tabular}


Figure 2. The validated structural model

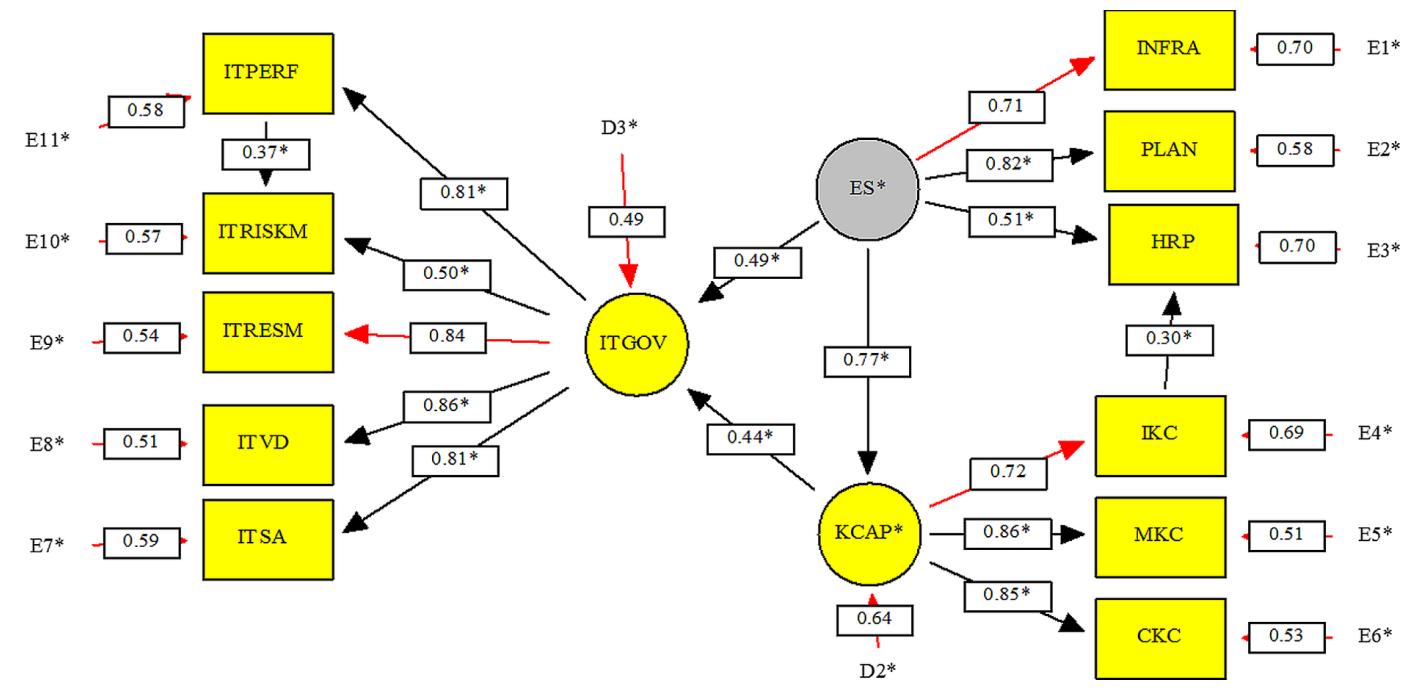

Table 3. Test statistics for the measurement models

\begin{tabular}{|c|c|c|c|c|}
\hline \multicolumn{5}{|c|}{ Test Statistics - Measurement Models } \\
\hline Regression Path & Standardized Beta $(\beta)$ & TTest & $\mathbf{R}^{2}$ & Significance@.05 \\
\hline \multicolumn{5}{|l|}{ ES (BI) Construct } \\
\hline INFRA & 0.71 & 20.14 & 0.51 & $\sqrt{ }$ \\
\hline PLAN & 0.82 & 15.82 & 0.67 & $\sqrt{ }$ \\
\hline HRP & 0.51 & 6.10 & 0.51 & $\sqrt{ }$ \\
\hline \multicolumn{5}{|l|}{ OKC Construct } \\
\hline IKC & 0.72 & 10.66 & 0.52 & $\sqrt{ }$ \\
\hline MKC & 0.86 & 16.48 & 0.74 & $\sqrt{ }$ \\
\hline CKC & 0.85 & 16.99 & 0.72 & $\sqrt{ }$ \\
\hline \multicolumn{5}{|l|}{ ITGOV Construct } \\
\hline ITSA & 0.81 & 22.45 & 0.65 & $\sqrt{ }$ \\
\hline ITVD & 0.86 & 22.26 & 0.74 & $\sqrt{ }$ \\
\hline ITResM & 0.84 & 2.84 & 0.72 & $\sqrt{ }$ \\
\hline ITRiskM & 0.50 & 5.82 & 0.68 & $\sqrt{ }$ \\
\hline ITPerfM & 0.81 & 21.50 & 0.66 & $\sqrt{ }$ \\
\hline
\end{tabular}

statically validated relationship between BI and each element does exist. Value of the TTest for the relationship in this construct was examined and validated as it did exceed the accepted value of 1.96 of 0.5 significate level thus the ES(BI) construct was confirmed

\section{Organizational Knowledge Capabilities Confirmatory Measurement Model Analysis}

OKC measurement model was used to investigate the second hypothesis which question the significant relationship between $\mathrm{OKC}$ and its elements (IKC, MKC, and CKC). To test the significant relation 
between the three elements of the OKC construct, the standardized beta was used to reflect on this relationship. Referring to Table 3, it did confirm the proposed relation and thus confirming the measurement model of OKC and it was significant @.05, so this indicate that all items are confirmed on $\mathrm{OKC}$ construct.

\section{IT Governance Confirmatory Measurement Model Analysis}

ITGOV measurement model was used to investigate third hypothesis which question the significance of the association of the IT Governance construct (System Alignment, Value Delivery, Resource Management, Risk Management and Performance Measurement). Testing ITGOV construct, the standardized beta was used to reflect on this relationship. The value of TTEST excide the required value of 1.96, all of TTest value as seen in Table 3 for the ITGOV construct are significant at 0.05 level.

\section{Structural Model Examination as the Path Analysis}

The Structural model comprises three measurement models (ES (BI), OKC, and ITGOV) was developed to investigate the possible significant associations between the two hypothesed regression paths $I T G O V=f b(E S)$, and $I T G O V=f b(O K C)$. Standardized significate beta was adopted as the lead indicator to confirm the proposed relationship for this construct. Table 4 shows a significate positive relationship between ES and ITGOV and OKC, where the value of test statistics (TTest) exceed the valid mark of 2.56 at 0.01 significates level for both suggested relationship. The coefficient of determination (R2) was also used to validate both hypotheses and results are illustrated in Figure 2 and Table 4.

As showed in Table 2 the structural model fit was accepted; all fit indexes were the required benchmark. All hypothesis was investigated and validated and the complete findings of the statistical examination did support the proposed framework developed in this study.

\section{CONCLUSION}

The objective of this study is to tap on and uncover the significance of the smart enterprise system as business intelligence and organizational knowledge capabilities and their roles in supporting and enhancing IT governance activities in business environment. The outcomes of the statistical analyses validate and support the notion that companies should look at the implementation process to their enterprise system as their business intelligence systems as it will have a profound effect on their IT governance and knowledge management activities. The general framework as presented in this research model and based on the findings as shown in Figure 2 suggest that as in statistical findings of the hypothesed and the adjusted model, businesses should focus on developing a smart infrastructure based on satisfying flexibility, availability scalability, reliability, performance. As far as planning in in concern, efforts in needed to work out an alignment strategies supported by a deep analysis and cooperation at the senior level. business should also put more emphasis on HR planned expertise

Table 4. The regression path analysis of the structure model

\begin{tabular}{|l|l|l|l|l|}
\hline \multicolumn{1}{|c|}{ Hypotheses } & \multicolumn{1}{|c|}{ Path } & \multicolumn{1}{c|}{ Standardized Beta $(\boldsymbol{\beta})$} & \multicolumn{1}{c|}{ TTEST } & \multicolumn{1}{c|}{ Sig @ .05 } \\
\hline H4 & $I T G O V=f b(E S)$ & 0.49 & 10.06 & $\sqrt{ }$ \\
\hline H5 & $I T G O V=f b(O K C)$ & 0.44 & 5.16 & $\sqrt{ }$ \\
\hline \multicolumn{2}{|l|}{ New unhypothesed results as a model adjustment } \\
\hline \multicolumn{2}{|l|}{$O K C=f b(E S)$} & 0.71 & 5.31 & $\sqrt{ }$ \\
\hline$H R P=f b 2(O K C)$ & 0.31 & 7.41 & $\sqrt{ }$ \\
\hline
\end{tabular}


and knowledge as it will guide the human resources planning efforts and will support professional capabilities of its staff and its end objectives of having competent staff that are able to perform and contributes to process of system development rational. Furthermore, this research reconfirms the elements of IT governance as shown in the study model and based on COBIT as a framework. The study highlights the imperious desires to create a conducive knowledge culture that sees information systems as a means and not as goal.

The findings of the articulated model that encompass the measurement models to reflect on status of ITGOV with both enterprise systems OKC, the study offers all-inclusive statistical argument about the procedures and methods that are utilized to revel the correct and proper application of smart enterprise systems. Finally, this study add new insight on unexpected relations and directions to the research field of information systems as there was little previously known detailed on the subject of business intelligence along with organizational knowledge capabilities and their role to enrich the IT Governance concept. In summary, this study examined the possible association among smart enterprise systems, organizational knowledge and IT Governance. The results showed that both organizational knowledge and IT governance were enhanced as a result of smart formation of the enterprise systems described here as a business intelligence systems. It's also observed that enterprise systems role applications have a more profound influence on organizational knowledge capabilities (OKC) comparing to IT governance (ITGOV), where OKC played a significate additive role in mediating the effect and thus provided an enhanced extra effect on IT governance. The final adjusted study model was presented to support the study topics and to help business organizations to apply correctly the discipline of enterprise systems. 


\section{REFERENCES}

Abate, R. (2009). IT Should be an Enabler to the Business. Information Management Blogs.

Adenfelt, M., \& Lagerstrom, K. (2006). Enabling knowledge creation and sharing in transnational projects. International Journal of Project Management, 24(3), 191-198. doi:10.1016/j.ijproman.2005.09.003

Al Qassimi, N., \& Rusu, L. (2015). IT Governance in a Public Organization in a Developing Country: A Case Study of a Governmental Organization. Procedia Computer Science, 64, 450-456. doi:10.1016/j.procs.2015.08.541

Al-Zayyat, A. N., Alkhaldi, F., Tadros, I., \& Al-Edwan, G. (2009). The effect of knowledge management processes on project management. IBIMA Business Review, 3, 47-52.

Alaceva, C., \& Rusu, L. (2014). Barriers in achieving business/IT alignment in a large Swedish company: What we have learned? Computers in Human Behavior.

Alreemy, Z., Chang, V., Walters, R., \& Wills, G. (2016). Critical success factors (CSFs) for information technology governance (ITG). International Journal of Information Management, 36(6), 907-916. doi:10.1016/j. ijinfomgt.2016.05.017

Aven, T. (2015). Risk assessment and risk management: Review of recent advances on their foundation. European Journal of Operational Research.

Azma, F., \& Mostafapour, M. A. (2012). Business intelligence as a key strategy for development organizations. Procedia Technology, 1, 102-106. doi:10.1016/j.protcy.2012.02.020

Blome, C., Schoenher, T., \& Eckstein, D. (2014). The impact of knowledge transfer and complexity on supply chain flexibility: A knowledge-based view. International Journal of Production Economics, 147, 307-316. doi:10.1016/j.ijpe.2013.02.028

Bowman, B., Davis, G., \& Wetherbe, J. (1983). Three stage model of MIS planning. Information \& Management, 6(1), 11-25. doi:10.1016/0378-7206(83)90016-2

Boynton, A. C., \& Zmud, R. W. (1987). Information technology planning in the 1990's: Directions for practice and research. Management Information Systems Quarterly, 11(1), 58-71. doi:10.2307/248826

Brown, I. T. (2006). Testing and Extending Theory in Strategic Information Systems Planning Through Literature Analysis. In M. Khosrow-Pour (Ed.), Advanced Topics in Information Resources Management (Vol. 5, pp. 282-318). Hershey, PA, USA: IGI Global. doi:10.4018/978-1-59140-929-8.ch013

Calvo-Mora, A., Navarro-García, A., \& Periañez-Cristobal, R. (2015). Project to improve knowledge management and key business results through the EFQM excellence model. International Journal of Project Management, 33(8), 1638-1651. doi:10.1016/j.ijproman.2015.01.010

Chan, R., \& Rosemann, M. (2001). Managing Knowledge in Enterprise Systems. Journal of Systems and Information Technology, 5(2), 37-54. doi:10.1108/13287260180000765

Chang, V. (2014). The business intelligence as a service in the cloud. Future Generation Computer Systems, 37 , 512-534. doi:10.1016/j.future.2013.12.028

Chang, V., Walters, R. J., \& Brian, G. (2016). Organisational sustainability modelling-An emerging service and analytics model for evaluating Cloud Computing adoption with two case studies. International Journal of Information Management, 36(1), 167-179. doi:10.1016/j.ijinfomgt.2015.09.001

Chang, V., Walters, R. J., \& Wills, G. (2013). The development that leads to the Cloud Computing Business Framework. International Journal of Information Management, 33(3), 524-538. doi:10.1016/j. ijinfomgt.2013.01.005

Cohen, J. F., \& Olsen, K. (2015). Knowledge management capabilities and firm performance: A test of universalistic, contingency and complementarity perspectives. Expert Systems with Applications, 42(3), 11781188. doi:10.1016/j.eswa.2014.09.002

Cunningham, J., Seaman, C., \& McGuire, D. (2015). Knowledge sharing in small family firms: A leadership perspective. Journal of Family Business Strategy. 
Davy, C. (2006). Recipients: The key to information transfer. Knowledge Management Research \& Practice, 4(1), 17-25. doi:10.1057/palgrave.kmrp.8500081

de Souza Bermejo, P. H., Tonelli, A. O., Zambalde, A. L., dos Santos, P. A., \& Zuppo, L. (2014). Evaluating IT Governance Practices and Business and IT Outcomes: A quantitative Exploratory Study in Brazilian Companies. Procedia Technology, 16, 849-857. doi:10.1016/j.protcy.2014.10.035

Delone, W. H., \& Mclean, E. R. (2003). The DeLone and McLean Model of Information Systems Success: A Ten-Year Update. Journal of Management Information Systems, 19(4), 9-3.

Doherty, N. F., Shakur, M., \& Ellis-Chadwick, F. (2015). The role of e-service quality management in the delivery business value. Journal of Retailing and Consumer Services, 27, 52-62. doi:10.1016/j.jretconser.2015.07.002

Drucker, P. (1999). Management challenges for the 21st century. New York: Harper Collins.

El-Mekawy, M., Rusu, L., \& Perjons, E. (2015). An evaluation framework for comparing business-IT alignment models: A tool for supporting collaborative learning in organizations. Computers in Human Behavior, 51, 1229-1247. doi:10.1016/j.chb.2014.12.016

Estrada, I., Faems, D., \& de Faria, P. (2015). Coopetition and product innovation performance: The role of internal knowledge sharing mechanisms and formal knowledge protection mechanisms. Industrial Marketing Management.

Gallinucci, E., Golfarelli, M., \& Rizzi, S. (2015). Advanced topic modeling for social business intelligence. Information Systems, 53, 87-106. doi:10.1016/j.is.2015.04.005

Gefen, D., Straub, D., \& Boudreau, M. C. (2000). Structural equation modeling and regression: Guidelines for research practice. Communications of the Association for Information Systems, 4(1), 7.

Gerschewski, S., \& Xiao, S. S. (2015). Beyond financial indicators: An assessment of the measurement of performance for international new ventures. International Business Review, 24(4), 615-629. doi:10.1016/j. ibusrev.2014.11.003

Ghani, A. T. A., \& Zakaria, M. S. (2013). Business-IT models drive businesses towards better value delivery and profits making. Procedia Technology, 11, 602-607. doi:10.1016/j.protcy.2013.12.234

Goldman, J. E., \& Ahuja, S. (2009). Integration of COBIT, Balanced Scorecard and SSE-CMM as a strategic Information Security Management (ISM) framework. Proceedings of the Fourth International Workshop on Business/IT Alignment and Interoperability (BUSITAL 2009), Amsterdam, The Netherlands.

Grant, G., \& Chen, Y. H. (2005). Measuring Enterprise Systems Capabilities: A Dynamic Capability Study. Proceedings of the Ninth Pacific Asia Conference on Information Systems PACIS '05 (pp. 1520-1526). Bangkok: Electronic Commerce Research Center, National Sun Yat-sen University.

Grovera, V., \& Segarsb, A. H. (2005). An empirical evaluation of stages of strategic information systems planning: Patterns of process design and effectiveness. Information \& Management, 42(5), 761-779. doi:10.1016/j. im.2004.08.002

Hair, J. F., Black, W. C., Babin, B. J., Anderson, R. E., \& Tatham, R. L. (2010). Multivariate data analysis (7th ed.). NY: Pearson.

Hammami, S., \& Alkhaldi, F. (2017). Individual, Managerial and Collaborative Capabilities of Organizational Knowledge. International Business Management, 11, 156-164.

Hammami, S., \& Alkhaldi, F. M. (2012). Enhancing BI Systems Application Through the Integration of IT Governance and Knowledge Capabilities of the Organization. In A. Rahman El Sheikh \& M. Alnoukari (Eds.), Business Intelligence and Agile Methodologies for Knowledge-Based Organizations: Cross-Disciplinary Applications (pp. 161-182). Hershey, PA: Business Science Reference; doi:10.4018/978-1-61350-050-7.ch008

Huotari, M.-L., \& Iivonen, M. (2004). Trust in Knowledge Management Systems in Organizations (M. KhosrowPour, Ed.). Hershey, USA: Idea Group Publishing. doi:10.4018/978-1-59140-126-1

Hyder, J. A., \& Hebl, J. R. (2015). Performance Measurement to Demonstrate Value. Anesthesiology Clinics, 33(4), 679-696. doi:10.1016/j.anclin.2015.07.007 PMID:26610623

ITGI. (2003). Board Briefing on IT Governance. IL: IT Governance Institute. 
ITGI. (2007). COBIT 4.1 Framework Control Objectives Management Guidelines Maturity Models. The IT Governance Institute. IL USA: The IT Governance Institute (ITGI). Retrieved from www.itgi.org

ITGI. (2008). IT Governance Roundtable: IT Governance Frameworks. IT Governance Institute.

Kubina, M., Koman, G., \& Kubinova, I. (2015). Possibility of Improving Efficiency within Business Intelligence Systems in Companies. Procedia Economics and Finance, 26, 300-305. doi:10.1016/S2212-5671(15)00856-4

Lederer, A. L., \& Sethi, V. (1988). The implementation of strategic information systems planning methodologies. Management Information Systems Quarterly, 12(3), 444-461. doi:10.2307/249212

Lucas, L. M. (2005). The impact of trust and reputation on the transfer of best practices. Journal of Knowledge Management, 9(4), 87-101. doi:10.1108/13673270510610350

Luftman, J. N. (2004). Managing the information technology resources. NJ: Pearson Prentice Hall.

Luftman, J. N., Bullen, C. V., Liao, D., Nash, E., \& Neumann, C. (2004). Managing the Information Technology Resource. New Jersey: Pearson Printice Hall.

Lunardi, G. L., Becker, J. L., Maçada, A., \& Dolci, P. (2014, March). The impact of adopting IT governance on financial performance: An empirical analysis among Brazilian firms. International Journal of Accounting Information Systems, 15(1), 66-81. doi:10.1016/j.accinf.2013.02.001

Malhotra, Y. (2005). Integrating knowledge management technologies in organizational business processes: Getting real time enterprises to deliver real business performance. Journal of Knowledge Management, 9(1), 7-28. doi:10.1108/13673270510582938

Mao, H., Liu, S., Zhang, J., \& Deng, Z. (2016). Information technology resource, knowledge management capability, and competitive advantage: The moderating role of resource commitment. International Journal of Information Management, 36(6), 1062-1074. doi:10.1016/j.ijinfomgt.2016.07.001

McGinnis, T. C., \& Zhenyu, H. (2007). Rethinking ERP success: A new perspective from knowledge management and continuous improvement. Information \& Management, 44(7), 626-634. doi:10.1016/j.im.2007.05.006

Moriarty, D. (2015). Introduction to human factors (pp. 1-10). In Practical Human Factors for Pilots.

Nabuco, O., Koyama, M. F., Pereira, E. D., \& Drira, K. (2006). Agent-Based System for Discovering and Building Collaborative Communities. In C. Ghaoui (Ed.), Encyclopedia of human computer interaction (pp. 12-17). Hershey, PA: IGI Global. doi:10.4018/978-1-59140-562-7.ch003

Nonaka, I., \& Konno, N. (1998). The concept of 'Ba': building a foundation for knowledge creation. California management review, 40(3), 40-54.

Ogiela, L., \& Ogiela, M. R. (2014, December). Cognitive systems for intelligent business information management in cognitive economy. International Journal of Information Management, 34(6), 751-760. doi:10.1016/j. ijinfomgt.2014.08.001

Pang, M. S. (2014). IT governance and business value in the public sector organizations-The role of elected representatives in IT governance and its impact on IT value in US state governments. Decision Support Systems, 59, 274-285. doi:10.1016/j.dss.2013.12.006

Pereira, R., \& da Silva, M. M. (2012). A literature review: IT governance guidelines and areas. Proceedings of the 6th International Conference on Theory and Practice of Electronic Governance (pp. 320-323). ACM. doi:10.1145/2463728.2463789

Peters, M. D., Wieder, B., Sutton, S. G., \& Wakefield, J. (2016). Business intelligence systems use in performance measurement capabilities: Implications for enhanced competitive advantage. International Journal of Accounting Information Systems, 21, 1-17. doi:10.1016/j.accinf.2016.03.001

Rebentisch, E. S., \& Ferretti, M. (1995). A knowledge asset-based view of technology transfer in international joint ventures. Journal of Engineering and Technology Management, 12, 1-25.

Rezaee, Z. (2016). Business sustainability research: A theoretical and integrated perspective. Journal of Accounting Literature. 
Rodríguez, J. U. L., \& Son, C. K. (2014). eGovernment standard framework. Proceedings of the 15th Annual International Conference on Digital Government Research (pp. 346-347). ACM. doi:10.1016/j.acclit.2016.05.003

Rowley, J. (1995). Strategic Information Systems Planning. Information Services \& Use, 15(1), 57-66.

Tanev, S., Liotta, G., \& Kleismantas, A. (2015). A business intelligence approach using web search tools and online data reduction techniques to examine the value of product-enabled services. Expert Systems with Applications, 42(21), 7582-7600. doi:10.1016/j.eswa.2015.06.006

Toledo, C. M., Chiotti, O., \& Galli, M. R. (2016). Process-aware approach for managing organisational knowledge. Information Systems, 62, 1-28. doi:10.1016/j.is.2016.04.001

Tseng, S. M. (2014). The impact of knowledge management capabilities and supplier relationship management on corporate performance. International Journal of Production Economics, 154, 39-47. doi:10.1016/j. ijpe.2014.04.009

Urban, W. (2015). The Lean Management Maturity Self-assessment Tool Based on Organizational Culture Diagnosis. Procedia: Social and Behavioral Sciences, 213, 728-733. doi:10.1016/j.sbspro.2015.11.527

Voon, P., \& Salido, J. (2009). MOF to COBIT/Val IT Comparison and Cross-Implementation Guide. Microsoft.

Zhang, Y. J., \& Harte, J. (2015). Population dynamics and competitive outcome derive from resource allocation statistics: The governing influence of the distinguishability of individuals. Theoretical Population Biology, 105, 53-63. doi:10.1016/j.tpb.2015.07.003 PMID:26226230

Zhu, Z., Zhao, J., Tang, X., \& Zhang, Y. (2015). Leveraging e-business process for business value: A layered structure perspective. Information \& Management, 52(6), 679-691. doi:10.1016/j.im.2015.05.004 